\title{
Single Nucleotide Polymorphisms within LIPA (Lysosomal Acid Lipase A) Gene Are Associated with Susceptibility to Premature Coronary Artery Disease. A Replication in the Genetic of Atherosclerotic Disease (GEA) Mexican Study
}

\author{
Gilberto Vargas-Alarcón ${ }^{1 *}$, Carlos Posadas-Romero², Teresa Villarreal-Molina ${ }^{3}$, Edith Alvarez-León', \\ Javier Angeles ${ }^{1}$, Maite Vallejo ${ }^{4}$, Rosalinda Posadas-Sánchez ${ }^{2}$, Guillermo Cardoso², Aida Medina-Urrutia², \\ Eric Kimura-Hayama ${ }^{5}$
}

1 Department of Molecular Biology, Instituto Nacional de Cardiología Ignacio, Chávez, Mexico City, Mexico, 2 Department of Endocrinology, Instituto Nacional de Cardiología Ignacio, Chávez, Mexico City, Mexico, 3 Cardiovascular Genomics Laboratory, Instituto Nacional de Medicina Genómica (INMEGEN), Mexico City, Mexico, 4 Sociomedical Department, Instituto Nacional de Cardiología Ignacio, Chávez, Mexico City, Mexico, 5 Department of Tomography, Instituto Nacional de Cardiología Ignacio, Chávez, Mexico City, Mexico

\begin{abstract}
Aim: The rs1412444 and rs2246833 polymorphisms within the LIPA gene were recently found to be significantly associated with coronary artery disease (CAD) in genome-wide association studies in Caucasian and Asian populations. The aim of the present study was to replicate this association in an independent population with a different genetic background.

Methods: The rs1412444 and rs2246833 polymorphisms of the LIPA gene were genotyped by $5^{\prime}$ exonuclease TaqMan genotyping assays in a sample of 899 Mexican patients with premature CAD, 270 individuals with subclinical atherosclerosis, and 677 healthy unrelated controls. Haplotypes were constructed after linkage disequilibrium analysis.

Results: Under recessive and additive models, the rs1412444 $T$ and rs2246833 $T$ alleles were associated with an increased risk of premature CAD when compared to controls adjusting for age, gender, BMI, and total cholesterol $\left(\mathrm{OR}=1.53, \mathrm{P}_{\mathrm{Rec}}=0.0013\right.$ and $\mathrm{OR}=1.34, \mathrm{P}_{\text {Add }}=5 \times 10^{-4}$ for $\mathrm{rs} 1412444$ and $\mathrm{OR}=1.45, \mathrm{P}_{\mathrm{Rec}}=0.0039$ and $\mathrm{OR}=1.28$, $\mathrm{P}_{\text {Add }}=0.0023$ for rs2246833). The effect of the two polymorphisms on various metabolic cardiovascular risk factors was analyzed in premature CAD and controls (CAC score $=0)$. The $T$ alleles in both polymorphisms after adjusting for age, gender, BMI, and medication were associated with hypo- $\alpha$-lipoproteinemia, hypercholesterolemia, hypertriglyceridemia, metabolic syndrome, and type 2 diabetes mellitus using recessive and additive models. The polymorphisms were in strong linkage disequilibrium and, based on SNP functional prediction software, only the rs1412444 polymorphism seemed to be functional.
\end{abstract}

Conclusions: These results indicate that the rs1412444 and rs2246833 of the LIPA gene are shared susceptibility polymorphisms for CAD among different ethnicities.

Citation: Vargas-Alarcón G, Posadas-Romero C, Villarreal-Molina T, Alvarez-León E, Angeles J, et al. (2013) Single Nucleotide Polymorphisms within LIPA (Lysosomal Acid Lipase A) Gene Are Associated with Susceptibility to Premature Coronary Artery Disease. A Replication in the Genetic of Atherosclerotic Disease (GEA) Mexican Study. PLoS ONE 8(9): e74703. doi:10.1371/journal.pone.0074703

Editor: Tanja Zeller, Medical University Hamburg, University Heart Center, Germany

Received April 30, 2013; Accepted August 5, 2013; Published September 17, 2013

Copyright: @ 2013 Vargas-Alarcón et al. This is an open-access article distributed under the terms of the Creative Commons Attribution License, which permits unrestricted use, distribution, and reproduction in any medium, provided the original author and source are credited.

Funding: This work was supported in part by grants from the Consejo Nacional de Ciencia y Tecnología (projects 156911 and 112547 ) and Fundación Gonzalo Rio Arronte, Mexico City, Mexico. The funders had no role in study design, data collection and analysis, decision to publish, or preparation of the manuscript.

Competing interests: The authors have declared that no competing interests exist.

*E-mail: gvargas63@yahoo.com 


\section{Introduction}

Coronary artery disease (CAD) is a complex multifactorial and polygenic disorder resulting from an excessive inflammatory response to various forms of injurious stimuli to the arterial wall [1-3]. Although the precise mechanisms responsible for the onset of the disease are still unknown, multiple genetic factors may cooperate with environmental factors to confer susceptibility to CAD. Genome wide association (GWA) studies have identified several genetic loci associated with the risk of CAD in different ethnic groups [4-9]. Results of association studies may vary between populations due to interpopulation genetic differences, including differences in allele frequencies and linkage disequilibrium (LD) structures [10]. Therefore, it is important to examine multiple ethnic populations through GWA studies for the identification of ethnicity-specific loci as well as common susceptibility loci. Recent GWA studies followed by two states of replication and a final meta-analysis in Caucasian individuals led to the identification of a novel CAD susceptibility locus on chromosome 10q23, 31, the LIPA (lysosomal acid lipase A) gene [11]. Monocyte gene expression analysis revealed an effect of LIPA single nucleotide polymorphisms (SNPs) on LIPA transcript levels. Two SNPs (rs1412444 and rs2246833) showed strong association with expression of the LIPA transcript levels. The LIPA gene encodes lysosomal acid lipase $(\mathrm{LAL})$, which hydrolyzes cholesteryl esters and triglycerides in the lysosome of cells to generate free cholesterol and free fatty acids [12]. Any alteration of LAL could produce an accumulation of triglycerides and cholesterol esters in the cell, resulting in foam cells and, consequently, in atherosclerotic plaque formation [13]. Patients with LAL deficiency show lipid accumulation in cells and develop premature atherosclerosis [14]. The role of the LIPA locus in CAD was corroborated in another GWA study in Caucasian and Asian populations [9]. Considering these studies, the aim of a present work was to determine whether the association of two SNPs with CAD, reported in Caucasian and Asian populations, is replicated in Mexican patients with premature CAD. The analysis of independent populations with different ethnic background often helps to unravel the genetic implications in associated regions by narrowing down the linkage structure.

\section{Materials and Methods}

All participants provided written informed consent, and the study complies with the Declaration of Helsinki and was approved by the Ethics Committee of the Instituto Nacional de Cardiología "Ignacio Chávez" (INCICH) and of the Instituto Nacional de Medicina Genómica. The primary aim of the GEA Study is to investigate genetic factors associated with premature $\mathrm{CAD}$, subclinical atherosclerosis, and other coronary risk factors in the Mexican population.

\section{Subjects}

All GEA participants are unrelated and of self-reported Mexican-Mestizo ancestry (3 generations). A Mexican Mestizo is defined as someone born in Mexico, who is a descendant of the original autochthonous inhabitants of the region and of individuals, mainly Spaniards, of Caucasian and/or African origin, who came to America during the sixteenth century. The study included 899 patients with premature CAD, 270 individuals with subclinical atherosclerosis (SA), and 677 healthy controls from the Genetic of Atherosclerotic Disease (GEA) Study. The selection of patients and controls of the GEA Study has been described previously [15]. Demographic, clinical, anthropometric, and biochemical parameters and cardiovascular risk factors were evaluated in patients and controls.

\section{Genetic analysis}

Genomic DNA from whole blood containing EDTA was isolated by standard techniques. The rs1412444 and rs2246833 single nucleotide polymorphisms (SNPs) were genotyped using 5' exonuclease TaqMan genotyping assays on an ABI Prism 7900HT Fast Real-Time PCR system, according to manufacturer's instructions (Applied Biosystems, Foster City, CA, USA)

\section{Statistical analysis}

All calculations were performed using SPSS version 18.0 (SPSS, Chicago, II) statistical package. Means \pm standard deviations (SD) and frequencies of baseline characteristics were calculated. Chi-square tests were used to compare frequencies and ANOVA and Student's t-test were used to compare means. ANCOVA was used to determine associations between the polymorphisms and metabolic variables, adjusting for age, gender, BMI, triglycerides, alcohol consumption, and smoking, as appropriate. Logistic regression analysis was used to test for associations of polymorphisms with premature CAD under inheritance models. The most appropriate inheritance model was selected based on Akaike information criteria and was adjusted for age, gender, BMI, triglycerides, alcohol consumption, and smoking. To address multiple testing, Bonferroni's correction was used considering five independent tests, and statistical significance was set at $p<0.01$. The statistical power estimated with QUANTO software (http:// hydra.usc.edu/GxE/) to detect association between premature CAD and controls was 0.96 for rs 1412444 and 0.90 for rs2246833, whereas to detect association between premature CAD and SA was 0.90 for rs1412444 and 0.77 for rs2246833. The power to detect association between SA and controls was low ( 0.1 for rs1412444 and 0.08 for rs2246833). Genotype frequencies did not show deviation from Hardy-Weinberg equilibrium (HWE) ( $p>0.05)$. Pairwise linkage disequilibrium (LD, D') estimations between polymorphisms and haplotype reconstruction were performed with Haploview version 4:1 (Broad Institute of Massachusetts Institute of Technology and Harvard University, Cambridge, MA, USA).

\section{Functional prediction analysis}

We predicted the potential effect of LIPA SNPs associated with premature $C A D$ in our population using bioinformatics tools, including FastSNP [16], SNP Function Prediction (http:// snpinfo.niehs.nih.gov/snpfunc.htm), Human-transcriptome Database for Alternative Splicing (http://www.h-invitational.jp/h- 
Table 1. Demographic characteristic of the population.

\begin{tabular}{|c|c|c|c|c|}
\hline & \multirow[b]{2}{*}{ CONTROL } & \multirow[b]{2}{*}{ SA } & \multicolumn{2}{|l|}{ Premature } \\
\hline & & & CAD & $\mathbf{P}^{*}$ \\
\hline & $(n=667)$ & $(n=270)$ & $(n=899)$ & \\
\hline Age (years) & $52.3 \pm 9.1$ & $58.7 \pm 8.4$ & $53.3 \pm 7.4$ & $<0.0001$ \\
\hline Gender (\% Male) & 38.1 & 72.6 & 82.6 & $<0.0001$ \\
\hline Body mass index $\left(\mathrm{kg} / \mathrm{m}^{2}\right)$ & $28.4 \pm 4.6$ & $28.8 \pm 4.5$ & $28.7 \pm 4.8$ & 0.2920 \\
\hline Obesity (\%) & 47.3 & 47.4 & 36.6 & $<0.0001$ \\
\hline Awaist circunference $(\mathrm{cm})$ & $93.4 \pm 11.7$ & $\begin{array}{l}97.4 \pm \\
11.1\end{array}$ & $98.6 \pm 11$ & $<0.0001$ \\
\hline Central Obesity (\%) & 79.6 & 82.2 & 83.7 & 0.1030 \\
\hline Total Abdominal Fat $\left(\mathrm{cm}^{2}\right)$ & $452.5 \pm 151.4$ & $\begin{array}{l}467.1 \pm \\
159.5\end{array}$ & $442.5 \pm 144.4$ & 0.0520 \\
\hline $\begin{array}{l}\text { Subcutaneous Abdominal } \\
\text { Fat }\left(\mathrm{cm}^{2}\right)\end{array}$ & $152.5 \pm 66.9$ & $\begin{array}{l}189.4 \pm \\
189.4\end{array}$ & $180.1 \pm 180.1$ & $<0.0001$ \\
\hline $\begin{array}{l}\text { Visceral Abdominal Fat } \\
\left(\mathrm{cm}^{2}\right)\end{array}$ & $152.5 \pm 66.9$ & $\begin{array}{l}189.4 \pm \\
68.3\end{array}$ & $180.1 \pm 73.3$ & $<0.0001$ \\
\hline $\begin{array}{l}\text { Visceral/Subcutaneous } \\
\text { adipose tissue ratio }\end{array}$ & $0.6 \pm 0.3$ & $0.8 \pm 0.3$ & $1.6 \pm 0.8$ & $<0.0001$ \\
\hline Current Smokers (\%) & 22.9 & 21.1 & 12.6 & $<0.0001$ \\
\hline Former Smokers (\%) & 31.6 & 45.2 & 64.4 & $<0.0001$ \\
\hline Hypertension (\%) & 54.5 & 50 & 67.1 & $<0.0001$ \\
\hline $\begin{array}{l}\text { Hypertensive Medication } \\
(\%)\end{array}$ & 15.4 & 28.5 & 66.8 & $<0.0001$ \\
\hline $\begin{array}{l}\text { Diastolic Blood Pressure } \\
(\mathrm{mmHg})\end{array}$ & $72.8 \pm 9.3$ & $\begin{array}{l}77.6 \pm \\
10.6\end{array}$ & $73.1 \pm 10.1$ & $<0.0001$ \\
\hline $\begin{array}{l}\text { Systolic Blood Pressure } \\
(\mathrm{mmHg})\end{array}$ & $118.3 \pm 17.2$ & $\begin{array}{l}128.2 \pm \\
20\end{array}$ & $119.7 \pm 18.8$ & $<0.0001$ \\
\hline Heart rate $(\mathrm{bpm})$ & $65.5 \pm 8.9$ & $\begin{array}{l}66.2 \pm \\
10.2\end{array}$ & $64.9 \pm 11.5$ & 0.2130 \\
\hline
\end{tabular}

Data are expressed as means $\pm S D$, log-transformed values were used for statistical analysis.

*. P values were computed using ANOVA for continuous variables and Pearson's Chi-square test for categorical values.

CAD: coronary artery disease; SA: subclinical atherosclerosis.

doi: 10.1371 /journal.pone.0074703.t001

dbas/), SplicePort (http://www.spliceport.cs.umd.edu/ SplicingAnalyser2.html), ESE finder

(http://rulai.cshl.edu/cgi-bin/tools/ESE3/esefinder.cgi), HSF

(http://www.umd.be/HSF), and SNPs3D (http:// www.snps3d.org/).

\section{Results}

\section{Characteristics of the study sample}

General characteristics of the population are shown in Tables 1 and 2 . Because $270(28.8 \%)$ of the apparently healthy individuals recruited as controls showed a positive coronary calcium score, three independent groups were considered for the analysis: controls (CAC score $=0)$, subclinical atherosclerosis (CAC score $>0$ ), and premature CAD.
Table 2. Comparison of biochemical parameters in individuals with premature coronary artery disease, subclinical atherosclerosis, and controls.

\begin{tabular}{|c|c|c|c|c|}
\hline & \multirow[b]{2}{*}{ CONTROL } & \multirow[b]{2}{*}{ SA } & \multicolumn{2}{|l|}{ Premature } \\
\hline & & & CAD & $\mathbf{P}^{*}$ \\
\hline & $(n=667)$ & $(n=270)$ & $(n=899)$ & \\
\hline Total Cholesterol (mg/dl) & $191.3 \pm 35.9$ & $198.3 \pm 37.2$ & $168.8 \pm 47.8$ & $<0.0001$ \\
\hline TC > $200 \mathrm{mg} / \mathrm{dl}(\%)$ & 35.3 & 47.4 & 21.7 & $<0.0001$ \\
\hline HDL-C (mg/dl) & $48.3 \pm 14.1$ & $44.6 \pm 11.7$ & $40.2 \pm 10.5$ & $<0.0001$ \\
\hline $\begin{array}{l}\text { Hipoa-lipoproteinemia } \\
(\%)\end{array}$ & 50.1 & 48.5 & 63.6 & $<0.0001$ \\
\hline LDL-C (mg/dl) & $116.4 \pm 31.8$ & $\begin{array}{l}124.0 \pm \\
31.03\end{array}$ & $97.6 \pm 39.2$ & $<0.0001$ \\
\hline Triglycerides (mg/dl) & $165.5 \pm 15.2$ & $\begin{array}{l}181.4 \pm \\
107.4\end{array}$ & $\begin{array}{l}192.9 \pm \\
124.3\end{array}$ & $<0.0001$ \\
\hline Hypertriglyceridemia (\%) & 45.2 & 53.3 & 58.4 & $<0.0001$ \\
\hline ApoAl (mg/dl) & $139.3 \pm 41.1$ & $138.9 \pm 36.6$ & $121.0 \pm 26.4$ & $<0.0001$ \\
\hline ApoB (mg/dl) & $89.7 \pm 27.5$ & $98.2 \pm 27.9$ & $23.8 \pm 16.3$ & $<0.0001$ \\
\hline $\begin{array}{l}\text { Statin and/or Fibrate } \\
\text { treatment (\%) }\end{array}$ & 7.4 & 12.2 & 94.7 & $<0.0001$ \\
\hline $\begin{array}{l}\text { Type } 2 \text { Diabetes mellitus } \\
(\%)\end{array}$ & 10.0 & 22.6 & 35.4 & $<0.0001$ \\
\hline Glucose (mg/dl) & $89.9 \pm 9.3$ & $93.0 \pm 9.7$ & $91.4 \pm 11.4$ & 0.0010 \\
\hline HOMA-IR & $4.4 \pm 2.7$ & $4.7 \pm 2.6$ & $5.1 \pm 3.3$ & $<0.0001$ \\
\hline $\begin{array}{l}\text { Alanine Transaminase } \\
\text { (IU/I) }\end{array}$ & $27.9 \pm 18.1$ & $27.3 \pm 17.6$ & $29.3 \pm 17.6$ & 0.1350 \\
\hline $\begin{array}{l}\text { Aspartate Transaminase } \\
\text { (IU/I) }\end{array}$ & $27.5 \pm 11.3$ & $28.6 \pm 13.9$ & $27.9 \pm 10.9$ & 0.4010 \\
\hline $\begin{array}{l}\text { Alkaline Phosphatase } \\
\text { (IU/I) }\end{array}$ & $84.2 \pm 23.7$ & $82.1 \pm 32.3$ & $80.3 \pm 25.6$ & 0.0150 \\
\hline $\begin{array}{l}\text { Gamma-glutamyl } \\
\text { transpeptidase (IU/I) }\end{array}$ & $34.7 \pm 31.5$ & $38.7 \pm 34.5$ & $45.1 \pm 43.4$ & $<0.0001$ \\
\hline
\end{tabular}

Data are expressed as means \pm SD, log-transformed values were used for statistical analysis.

*. $\mathrm{P}$ values were computed using ANOVA for continuous variables and Pearson's Chi-square test for categorical values.

CAD: coronary artery disease; SA: subclinical atherosclerosis.

doi: 10.1371/journal.pone.0074703.t002

\section{Association of polymorphisms with premature CAD}

Observed and expected frequencies in the polymorphic sites were in HWE. The distribution of the rs1412444 and rs2246833 polymorphisms was similar in patients with subclinical atherosclerosis and healthy controls, but different in patients with premature CAD. The rs $1412444 T$ allele was significantly associated with an increased risk of premature CAD as compared to controls under both recessive and additive models adjusting for age, gender, $\mathrm{BMI}$, and total cholesterol $(\mathrm{OR}=$ $1.53,95 \% \mathrm{Cl}: 1.18-1.99, \mathrm{P}_{\text {rec }}=0.0013$ and $\mathrm{OR}=1.34,95 \% \mathrm{Cl}$ : 1.14-1.58, $\mathrm{P}_{\text {add }}=5 \times 10^{-4}$ ) and as compared to SA under dominant and additive models adjusted by the same variables $\left(\mathrm{OR}=1.74,95 \% \mathrm{Cl}: 1.23-2.48, \mathrm{P}_{\text {dom }}=0.0021\right.$ and $\mathrm{OR}=1.31$, $\left.95 \% \mathrm{Cl}: 1.06-1.62, \mathrm{P}_{\text {add }}=0.0110\right)$. On the other hand, the rs2246833 $T$ allele was significantly associated with increased risk of premature $C A D$ as compared to controls under both 
Table 3. Association of the $(C>T)$ rs 1412444 and $(C>T)$ rs2246833 polymorphisms with premature coronary artery disease and subclinical atherosclerosis.

\begin{tabular}{|c|c|c|c|c|c|c|c|}
\hline \multirow[t]{2}{*}{ rs1412444 } & \multicolumn{7}{|c|}{$\begin{array}{l}\text { GENOTYPE } \\
\text { FREQUENCY (\%) }\end{array}$} \\
\hline & $\overline{C / C}$ & $\mathrm{C} / \mathrm{T}$ & $T / T$ & RAF & MODEL & OR (95\% Cl) & $P$ \\
\hline $\begin{array}{l}\text { CONTROL } \\
(n=677)\end{array}$ & 0.258 & 0.501 & 0.241 & 0.491 & & & \\
\hline $\begin{array}{l}S A(n= \\
270)\end{array}$ & 0.263 & 0.459 & 0.278 & 0.493 & & & \\
\hline $\begin{array}{l}\text { Premature } \\
\text { CAD ( } n= \\
899)\end{array}$ & 0.200 & 0.479 & 0.321 & 0.561 & Recessive $†$ & $\begin{array}{l}1.53 \\
(1.18-1.99)\end{array}$ & 0.0013 \\
\hline & & & & & Additive $†$ & $\begin{array}{l}1.34 \\
(1.14-1.58)\end{array}$ & $5 \times 10^{-4}$ \\
\hline & & & & & Dominant $^{\ddagger}$ & $\begin{array}{l}1.74 \\
(1.23-2.48)\end{array}$ & 0.0021 \\
\hline & & & & & Additive $^{\ddagger}$ & $\begin{array}{l}1.31 \\
(1.06-1.62)\end{array}$ & 0.0110 \\
\hline \multirow[t]{2}{*}{ rs2246833 } & $\begin{array}{l}\text { GENO } \\
\text { FREQ }\end{array}$ & $\begin{array}{l}\text { TYPE } \\
\text { JENCY ( }\end{array}$ & & & & & \\
\hline & $\mathrm{C} / \mathrm{C}$ & $\mathrm{C} / \mathrm{T}$ & $T / T$ & RAF & MODEL & $\begin{array}{l}\text { OR }(95 \% \\
\mathrm{Cl})\end{array}$ & $\mathbf{P}$ \\
\hline $\begin{array}{l}\text { CONTROL } \\
(\mathrm{n}=677)\end{array}$ & 0.247 & 0.502 & 0.251 & 0.502 & & & \\
\hline $\begin{array}{l}\text { SA }(n= \\
270)\end{array}$ & 0.259 & 0.456 & 0.285 & 0.513 & & & \\
\hline $\begin{array}{l}\text { Premature } \\
\text { CAD ( } n= \\
899)\end{array}$ & 0.196 & 0.482 & 0.323 & 0.563 & Recessive† & $\begin{array}{l}1.45 \\
(1.12-1.87)\end{array}$ & 0.0039 \\
\hline & & & & & Additive $†$ & $\begin{array}{l}1.28 \\
(1.09-1.51)\end{array}$ & 0.0023 \\
\hline & & & & & Dominant $^{\ddagger}$ & $\begin{array}{l}1.60 \\
(1.14-2.23)\end{array}$ & 0.0071 \\
\hline & & & & & Additive $^{\ddagger}$ & $\begin{array}{l}1.26 \\
(1.03-1.54)\end{array}$ & 0.0230 \\
\hline
\end{tabular}

Associations were tested using logistic regression adjusting for age, gender, BMI, and TC levels.

SA: subclinical atherosclerosis; CAD: coronary artery disease; RAF: risk allele frequency.

† Compared to controls.

¥. Compared to individuals with subclinical atherosclerosis

No differences were observed when comparing SA individuals with controls doi: 10.1371 /journal.pone.0074703.t003

recessive and additive models adjusted by age, gender, BMI, and total cholesterol $\left(\mathrm{OR}=1.45,95 \% \mathrm{Cl}: 1.12-1.87, \mathrm{P}_{\mathrm{rec}}=\right.$ 0.0039 and $\left.\mathrm{OR}=1.28,95 \% \mathrm{Cl}: 1.09-1.51, \mathrm{P}_{\text {add }}=0.0023\right)$ and as compared to SA under dominant and additive models adjusted by the same variables $(\mathrm{OR}=1.60,95 \% \mathrm{Cl}$ : 1.14-2.23, $P_{\text {dom }}=0.0071$ and $\mathrm{OR}=1.26,95 \% \mathrm{Cl}: 1.03-1.54, \mathrm{P}_{\text {add }}=$ 0.0230 ) (Table 3). The two LIPA polymorphisms were in strong linkage disequilibrium $\left(D^{\prime}=0.980, r^{2}=0.937\right.$ ) forming four haplotypes (data not shown).
Table 4. Association of the (C > T) rs1412444 polymorphism with coronary risk factors.

\begin{tabular}{|c|c|c|c|c|c|}
\hline & & RAF & & & \\
\hline & RAF & Premature & & & \\
\hline & Controls & CAD & MODEL & OR $(95 \% \mathrm{Cl})$ & $\mathbf{P}$ \\
\hline \multirow[t]{3}{*}{$\begin{array}{l}\text { Hypo- } \alpha- \\
\text { lipoproteinemia }\end{array}$} & $\begin{array}{l}(n= \\
339)\end{array}$ & $(n=572)$ & Recessive & $\begin{array}{l}2.50 \\
(1.24-5.02)\end{array}$ & 0.0087 \\
\hline & 0.492 & 0.548 & & & \\
\hline & & & Additive & $\begin{array}{l}1.90 \\
(1.24-2.93)\end{array}$ & 0.0028 \\
\hline \multirow[t]{3}{*}{ Hypercholesterolemia } & $\begin{array}{l}(n= \\
245)\end{array}$ & $(n=198)$ & Recessive & $\begin{array}{l}2.63 \\
(1.03-6.75)\end{array}$ & 0.0370 \\
\hline & 0.481 & 0.588 & & & \\
\hline & & & Additive & $\begin{array}{l}1.96 \\
(1.12-3.41)\end{array}$ & 0.0180 \\
\hline \multirow[t]{3}{*}{ Hypertriglyceridemia } & $\begin{array}{l}(n= \\
306)\end{array}$ & $(n=528)$ & Recessive & $\begin{array}{l}2.07 \\
(1.10-3.88)\end{array}$ & 0.0200 \\
\hline & 0.503 & 0.574 & & & \\
\hline & & & Additive & $\begin{array}{l}1.85 \\
(1.26-2.72)\end{array}$ & 0.0015 \\
\hline \multirow[t]{3}{*}{ Metabolic Syndrome } & $\begin{array}{l}(n= \\
277)\end{array}$ & $(n=428)$ & Recessive & $\begin{array}{l}2.57 \\
(1.35-4.89)\end{array}$ & 0.0022 \\
\hline & 0.503 & 0.554 & & & \\
\hline & & & Additive & $\begin{array}{l}1.94 \\
(1.34-2.82)\end{array}$ & 0.0003 \\
\hline \multirow[t]{3}{*}{$\begin{array}{l}\text { Type } 2 \text { Diabetes } \\
\text { Mellitus }\end{array}$} & $(n=68)$ & $(n=325)$ & Recessive & $\begin{array}{l}2.64 \\
(1.27-5.50)\end{array}$ & 0.0060 \\
\hline & 0.455 & 0.578 & & & \\
\hline & & & Additive & $\begin{array}{l}1.83 \\
(1.19-2.81)\end{array}$ & 0.0051 \\
\hline \multicolumn{6}{|c|}{$\begin{array}{l}\text { All association were tested using logistic regression adjusted for age, gender, BMI, } \\
\text { and medication when appropriate. (n) Represents the number of cases with each } \\
\text { trait. } \\
\text { RAF: risk allele frequency. }\end{array}$} \\
\hline
\end{tabular}

Association of the polymorphisms with metabolic cardiovascular risk factors and metabolic parameters

The effect of the two polymorphisms on various metabolic cardiovascular risk factors was analyzed in premature $C A D$ and controls (CAC score $=0$ ). The $T$ alleles of both polymoprhisms after adjusting for age, gender, BMI, and medication were associated with hypo-a-lipoproteinemia, hypercholesterolemia, hypertriglyceridemia, metabolic syndrome, and type 2 diabetes mellitus using recessive and additive models (Tables 4 and 5). On the other hand, the effect of the polymorphisms on metabolic parameters was explored separately in controls (CAC score $=0$ ), subclinical atherosclerosis (CAC score $>0$ ), and premature CAD. No association with metabolic parameters was observed in any study group (data not shown). 
Table 5. Association of the $(\mathrm{C}>\mathrm{T})$ rs2246833 polymorphism with coronary risk factors.

\begin{tabular}{|c|c|c|c|c|c|}
\hline & & RAF & & & \\
\hline & RAF & Premature & & & \\
\hline & Controls & CAD & MODEL & OR $(95 \% \mathrm{Cl})$ & $\mathbf{P}$ \\
\hline \multirow[t]{3}{*}{$\begin{array}{l}\text { Нуро- } \alpha- \\
\text { lipoproteinemia }\end{array}$} & $\begin{array}{l}(n= \\
339)\end{array}$ & $(n=572)$ & Recessive & $\begin{array}{l}2.51 \\
(1.25-5.04)\end{array}$ & 0.0079 \\
\hline & 0.492 & 0.548 & & & \\
\hline & & & Additive & $\begin{array}{l}2.01 \\
(1.31-3.10)\end{array}$ & 0.0011 \\
\hline \multirow[t]{2}{*}{ Hypercholesterolemia } & $\begin{array}{l}(n= \\
245)\end{array}$ & $(n=198)$ & & & \\
\hline & 0.481 & 0.588 & Additive & $\begin{array}{l}1.91 \\
(1.10-3.34)\end{array}$ & 0.0200 \\
\hline \multirow[t]{3}{*}{ Hypertriglyceridemia } & $\begin{array}{l}(n= \\
306)\end{array}$ & $(n=528)$ & Recessive & $\begin{array}{l}2.02 \\
(1.08-3.79)\end{array}$ & 0.0230 \\
\hline & 0.503 & 0.574 & & & \\
\hline & & & Additive & $\begin{array}{l}1.92 \\
(1.30-2.83)\end{array}$ & 0.0008 \\
\hline \multirow[t]{2}{*}{ Metabolic Syndrome } & $\begin{array}{l}(n= \\
277)\end{array}$ & $(n=428)$ & & & \\
\hline & 0.503 & 0.554 & Additive & $\begin{array}{l}1.71 \\
(1.19-2.45)\end{array}$ & 0.0033 \\
\hline \multirow[t]{3}{*}{$\begin{array}{l}\text { Type } 2 \text { Diabetes } \\
\text { Mellitus }\end{array}$} & $(n=68)$ & $(n=325)$ & Recessive & $\begin{array}{l}2.08 \\
(1.03-4.18)\end{array}$ & 0.0330 \\
\hline & 0.455 & 0.578 & & & \\
\hline & & & Additive & $\begin{array}{l}1.79 \\
(1.17-2.74)\end{array}$ & 0.0062 \\
\hline
\end{tabular}

All association were tested using logistic regression adjusted for age, gender, BMI, and medication when appropriate. ( $n$ ) Represents the number of cases with each trait.

RAF: risk allele frequency.

doi: 10.1371 /journal.pone.0074703.t005

\section{Discussion}

In this study, we observed that two LIPA polymorphisms previously identified in a GWA study in Caucasian and Asian populations (rs1412444 and rs2246833) are also associated with premature CAD in the Mexican population [9,11]. It is important to point out that subclinical atherosclerosis was ruled out among controls by computed tomography, only including individuals with calcium score $=0$. Individuals initially recruited as controls with calcium score $>0$ were studied as an independent group with SA. It is noteworthy that, although in a previous study in Caucasians, these polymorphisms were also associated with LIPA expression and that this expression was related to subclinical disease assessed by vascular endothelial function [11]. In the present study no differences in allele frequencies were observed between controls and individuals with subclinical atherosclerosis assessed by computed tomography. However, this may be due to the low statistical power considering the sample size of the group of individuals with SA included in the study. On comparing this study with that reported by Wild et al. [11] there are some differences in study design. While Wild et al. included only patients with severe coronary atherosclerosis documented by angiography and myocardial infarction, our study included patients with unstable angina. In addition, we included only patients with premature CAD diagnosed before age 55 in men and age 65 in women. This suggests that LIPA polymorphisms are associated with $C A D$ independently from the severity and age of onset of the disease.

The LIPA gene is a biological candidate for CAD and dyslipidemia because it is involved in cholesteryl ester and triglyceride hydrolysis in lysosomes to generate free cholesterol and free fatty acids, and, consequently, plays a role in atherosclerotic plaque formation. Moreover, individuals heterozygous for the E8SJM LIPA mutations were found to have altered lipid profiles with a polygenic hypercholesterolemia phenotype, leading to an increase in cardiovascular risk profile [17]. The association of the LIPA polymorphisms with metabolic and coronary risk factors had been analyzed previously with contradictory results. Wild et al. [11] reported that elevated LIPA expression was significantly associated with lower HDL-cholesterol levels and impaired endothelial function measured by flow-mediated vasodilatation, whereas associations with higher levels of LDL-cholesterol and triglycerides did not reach statistical significance. In contrast, no significant association between LIPA polymorphisms and any cardiovascular risk factor was observed. The IBC 50K CAD Consortium [18] reported no association between LIPA polymorphisms and altered lipid levels. We thus explored whether LIPA polymorphisms were associated with other metabolic cardiovascular risk factors, finding that these polymorphisms were significantly associated with hypo- $\alpha-$ lipoproteinemia, hypercholesterolemia, hypertriglyceridemia, metabolic syndrome, and type 2 diabetes mellitus in premature CAD patients. Novel in the present study is the association between LIPA polymorphisms and different metabolic traits. This first time report on the associations of LIPA polymorphisms with metabolic traits needs to be confirmed in other studies.

LIPA polymorphisms, rs1412444 and rs2246833, were found to be significantly associated with increased LIPA expression levels [11]. This increase might enhance intracellular release of fatty acids and cholesterol via the lysosomal route, explaining the role of LIPA in atherosclerosis [19]. On the other hand, the increased LIPA expression may produce an increased LALactivity, generating an increase in the cholesteryl ester hydrolysis. It is well known that cholesteryl ester hydrolysis participates in the enzymatic modification of LDL particles, transforming them into proatherogenic particles [20]. Only two studies reported previously the effect of the rs1412444 and rs2246833 polymorphisms in LIPA expression levels. In these studies, both polymorphisms (rs1412444 and rs2246833) were associated with increased expression levels of LIPA $[11,18]$. However, gene expression studies performed in monocytes and other cell types might yield different results. Considering that no other studies have reported this functional effect, we decided to perform a functional prediction analysis. Based on SNP functional prediction software (http://snpinfo.niehs.nih.gov/ snpfunc.htm), only the rs1412444 polymorphism seems to be functional. In this case, the presence of the $T$ allele produces a 
loss (or reduction) of DNA binding of transcription factors with ETS domain with important consequences on the expression of the lysosomal acid lipase. Conserved ETS DNA-binding domains mediate transcriptional regulation at ETS sequencecontaining promoters and contain many phosphorylation sites targeted by various MAP kinases, following exposure to cell stressors or mitogenic stimuli [21]. However, this predicted functional consequences of the rs1412444 $T$ allele needs experimental testing. Considering the possible functional effect of these polymorphisms, the association of rs2246833 with premature $C A D$ could be due to linkage disequilibrium with rs1412444.

\section{Conclusion}

In summary, our results replicate two polymorphisms, which were proven to be associated with CAD in Caucasian and Asian populations in Mexican patients with premature CAD.

\section{References}

1. Ross $R$ (1999) Atherosclerosis an inflammatory disease. N Engl J Med 340: 115-126. doi:10.1056/NEJM199901143400207. PubMed: 9887164.

2. García-Moll X (2005) Inflammatory and Anti-Inflammatory Markers in Acute Coronary Syndromes. Ready for Use in the Clinical Setting? Rev Esp Cardiol 58: 615-617. doi:10.1157/13076412. PubMed: 15970115.

3. Lusis AJ (2000) Atherosclerosis. Nature 407: 233-241. doi: 10.1038/35025203. PubMed: 11001066.

4. CARDIoGRAMplusC4D Consortium (2013) Large-scale association analysis identifies new risk loci for coronary artery disease. Nat Genet 45: 25-33. PubMed: 23202125

5. O'Donnell CJ, Kavousi M, Smith AV, Kardia SL, Feitosa MF et al. (2011) Genome-wide association study for coronary artery calcification with follow-up in myocardial infarction. Circulation 124: 2855-2864. doi: 10.1161/CIRCULATIONAHA.110.974899. PubMed: 22144573.

6. Schunkert H, König IR, Kathiresan S, Reilly MP, Assimes TL et al. (2011) Large-scale association analysis identifies 13 new susceptibility loci for coronary artery disease. Nat Genet 43: 333-338. doi: 10.1038/ng.784. PubMed: 21378990

7. Lee JY, Lee BS, Shin DJ, Woo Park K, Shin YA et al. (2013) A genome-wide association study of a coronary artery disease risk variant. J Hum Genet 58: 120-126. doi:10.1038/jhg.2012.124. PubMed: 23364394.

8. Lu X, Wang L, Chen S, He L, Yang X et al. (2012) Genome-wide association study in Han Chinese identifies four new susceptibility loci for coronary artery disease. Nat Genet 44: 890-894. doi:10.1038/ng. 2337. PubMed: 22751097.

9. The Coronary Artery Disease (C4D). Genetics Consortium (2011) A genome-wide association study in Europeans and South Asians identifies five new loci for coronary artery disease. Nat Genet 43 : 339-344.

10. Neale BM, Sham PC (2004) The Future of Association Studies: GeneBased Analysis and Replication. Am J Hum Genet 75: 353-362. doi: 10.1086/423901. PubMed: 15272419.

11. Wild PS, Zeller T, Schillert A, Szymczak S, Sinning CR et al. (2011) A genome-wide association study identifies LIPA as a susceptibility gene
This is the first study that reports the association of LIPA polymorphisms with CAD in a non-Caucasian- and non-Asianorigin population, suggesting that rs1412444 and rs2246833 of the LIPA gene are shared susceptibility polymorphisms for CAD among different ethnicities. Novel associations of LIPA polymorphisms with metabolic traits were also reported.

\section{Acknowledgements}

The authors are grateful to the study participants.

\section{Author Contributions}

Conceived and designed the experiments: GVA CPR. Performed the experiments: RPS EAL GC AMU. Analyzed the data: MV JA. Contributed reagents/materials/analysis tools: EKH CPR TVM. Wrote the manuscript: GVA TVM. for coronary artery disease. Circ Cardiovasc Genet 4: 403-412. doi: 10.1161/CIRCGENETICS.110.958728. PubMed: 21606135.

12. Brown MS, Goldstein JL (1986) A receptor-mediated pathway for cholesterol homeostasis. Science 232: 34-47. doi:10.1126/science. 3513311. PubMed: 3513311.

13. Zschenker O, Illies T, Ameis D (2006) Overexpression of Iysosomal acid lipase and other proteins in atherosclerosis. J Biochem 140: 23-38. doi:10.1093/jb/mvj137. PubMed: 16877765.

14. Bernstein DL, Hülkova H, Bialer MG, Desnick RJ (2013) Cholesteryl ester storage disease: review of the findings in 135 reported patients with an underdiagnosed disease. J Hepatol 58: 1230-1243. doi: 10.1016/j.jhep.2013.02.014. PubMed: 23485521.

15. Villarreal-Molina T, Posadas-Romero C, Romero-Hidalgo S, AntúnezArgüelles E, Bautista-Grande A et al. (2012) The ABCA1 gene R230C variant is associated with decreased risk of premature coronary artery disease: the genetics of atherosclerotic disease (GEA) study. PLOS ONE 7: e49285. doi:10.1371/journal.pone.0049285. PubMed: 23152888.

16. Yuan HY, Chiou JJ, Tseng WH, Liu CH, Liu CK et al. (2006) FASTSNP: an always up-to-date and extendable service for SNP function analysis and prioritization. Nucleic Acids Res 34: W635-41 (Web Server issue [accessed on 2012]. PubMed: 16845089.

17. Muntoni $S$, Wiebusch $H$, Jansen-Rust $M$, Rust $S$, Schulte $H$ et al. (2013) Heterozygosity for lysosomal acid lipase E8SJM mutation and serum lipid concentrations. Nutr Metab Cardiovasc Dis 23: 732-736. doi:10.1016/j.numecd.2012.05.009. PubMed: 22795295.

18. IBC 50K CAD Consortium (2011) Large-scale gene-centric analysis identifies novel variants for coronary artery disease. PLoS Genet. 7:e1002260

19. Zschenker O, Illies T, Ameis D (2006) Overexpression of lysosomal acid lipase and other proteins in atherosclerosis. J Biochem 140: 23-38. doi:10.1093/jb/mvj137. PubMed: 16877765

20. Bhakdi S, Lackner KJ, Han SR, Torzewski M, Husmann M (2004) Beyond cholesterol: the enigma of atherosclerosis revisited. Thromb Haemost 91: 639-645. PubMed: 15045123.

21. Hollenhorst PC, Shah AA, Hopkins C, Graves BJ (2007) Genome-wide analyses reveal properties of redundant and specific promoter occupancy within the ETS gene family. Genes Dev 21: 1882-1894. doi: 10.1101/gad.1561707. PubMed: 17652178. 